\title{
O hiperencarceramento brasileiro sob perspectiva de gênero e raça
}

The brazilian incarceration from the perspective of race and gender

\author{
Maria Carolina Cardim das Neves \\ carolinacardim4@gmail.com \\ Graduanda em Ciências Sociais pela \\ PUCRio e Administração pela UFRRJ
}

\section{Resumo}

O Brasil é o quarto país do mundo em que mais existem mulheres encarceradas, conforme os dados apresentados pelo Levantamento Nacional de Informações Penitenciárias das Mulheres (Infopen Mulheres) em 2018. E nos últimos anos o encarceramento de mulheres aumentou, ficando inclusive superior à média de encarceramento de homens. Como técnica metodológica, foram realizadas pesquisas a documentos em nível estadual, nacional e internacional.

Palavras-chave: mulheres negras; encarceramento feminino; políticas públicas.

\begin{abstract}
Brazil is the fourth country in the world in which there are more women incarcerated according to data presented by Infopen Women in 2016. And in recent years the incarceration of women has increased exponentially, even exceeding the average incarceration of men. As a methodological technique, searches were made for documents at the state, national and international levels.
\end{abstract}

Keywords: black women; prison system; public policy. 


\section{O corpo da mulher negra e sua criminalização}

A raça é uma construção histórica, visto que não é um componente biológico. Assim, a ideologia racista é uma produção construída historicamente que permanece até hoje, de forma que regula a vivência do outro a partir de sua etnia, padronizando a vida social. Para Almeida (2019, p.19-20) “o racismo é parâmetro de normalidade da vida social e política. [...] Ideologia é a maneira como nós constituímos a nossa forma de ver o mundo, é o nosso fundo de constituição subjetiva, ela constitui sujeitos." As teorias da supremacia dos homens e do povo ariano foram algumas das correntes de pensamento que se propagaram pelo mundo de maneira impositiva por meio de ações desumanas e trágicas, como a diáspora africana. Oriundos dessas correntes de pensamento, surgem o racismo, o sexismo e a discriminação por classe social, mediante os quais as mulheres negras são interceptadas diversas vezes.

A partir do processo histórico do racismo instituído no Brasil desde a escravidão, corpos de mulheres negras são culpabilizados por estupros acontecidos na época colonial, com a justificativa de que seriam irresistíveis e quentes. As mulheres negras eram duas vezes castigadas e, além dos suplícios, também eram violentadas sexualmente. Essa degradação do corpo feminino negro foi ultrapassando os séculos e se faz presente quando somos as maiores vítimas de violência doméstica e sexual, de feminicídio. É ainda presente no aumento do encarceramento de mulheres negras confirmando costumes que se concretizam na violência física ou psicológica dessas mulheres, baseados no racismo e sexismo. Como a pesquisadora Juliana Borges aponta:

\footnotetext{
Ao analisarmos o período escravocrata, devemos olhar os estupros e relações sexuais por coerção de senhores contra mulheres negras escravizadas também neste âmbito do sistema punitivo privado. Destas relações também tivemos a construção de estereótipos hipersexualizados de mulheres negras e que apresentam resquícios no sistema penal ainda hoje. E esta visão hipersexualizada e racializada, principalmente, de uma relação totalmente desigual de poder, que se estabelece entre criminalidade e sexualidade potencializando estas vulnerabilidades no interior do sistema prisional. (2018, p.93)
}

Com a criminalização da escravidão, foram encontrados outros artifícios para a dominação e repressão do corpo negro e seus costumes. O Estado Brasileiro propaga a ideia de que o jovem negro é uma ameaça à sociedade e deve ser exterminado a partir de políticas genocidas, o que se confirma a partir do fato de que a maior taxa de assassinato por arma de 
fogo é de negros, especialmente entre de jovens de 15 a 29 anos. Conforme o Mapa da Violência, em 2014, "morrem 2,6 vezes mais negros que brancos vitimados por arma de fogo" (Waiselfisz, 2016, p.72). Segundo o levantamento do Sistema Nacional de Atendimento Socioeducativo (Sinase) ( 2018, p.19), 59,08\% dos adolescentes em restrição ou privação de liberdade são classificados pretos ou pardos. Ainda, $50 \%$ da população feminina encarcerada é jovem, por volta dos seus 20 anos (Borges, 2018, p.91). O número de internação de adolescentes negras vem aumentando nos últimos anos, ficando evidente que o racismo e o sexismo são ideologias que fazem parte das instituições do Estado.

Há de se atentar para o fato de que, a partir da Lei de Drogas (Brasil, 2006), o número de adolescentes no sistema de internação feminino aumentou. A política de guerra às drogas, baseada principalmente nas políticas públicas dos Estados Unidos de tolerância zero, não busca distinguir traficantes de usuário, ou aqueles que têm cargos menores como "mulas", "olheiros", ou mesmo aqueles que embalam as drogas, funções que a maioria dos adolescentes ocupa. $\mathrm{O}$ ex-ministro da Justiça, Sérgio Moro, formulou, em 2019, um projeto de lei que alterou essa Lei de Drogas, adotando medidas mais severas em relação a entorpecentes ilícitos, mas ainda não deixando claro quem seria considerado traficante ou não (Brasil, 2019). Tendo em vista que o tráfico de drogas é um dos maiores motivos pelos quais as mulheres são presas, esse projeto de lei acaba por incentivar ainda mais o aumento da internação dessas jovens. Além de legitimar a violência policial, ele também flexibiliza a redução ou anulação da pena para o policial quando ele agir em legítima defesa, com escusável medo, surpresa ou violenta emoção (Brasil, 2019), não definindo também quais seriam essas ações, deixando totalmente a cargo do juiz. Em um país em que abuso de poder por parte dos policiais é algo recorrente com a população menos favorecida, esse tipo de projeto de lei acaba sendo seletivo e atinge diretamente determinada parte da população.

O teórico crítico Michel Foucault, em seu importante estudo em Vigiar e Punir (1987), salienta que a disciplina como técnica é centralizada no corpo, provocando efeitos individualizantes, manipulando-o de tal forma que o torne útil e dócil. Com sua transformação, a técnica passa a não ser mais centrada no corpo, mas sim na vida; ela passa a reproduzir efeitos de massa em que se procura controlar eventos fortuitos que podem ocorrer em uma população.

"Adestra" as multidões confusas, móveis, inúteis de corpos e forças para uma multiplicidade de elementos individuais - pequenas células separadas, autonomias orgânicas, identidades e continuidades genéticas, segmentos combinatórios. A disciplina "fabrica" indivíduos; ela é a técnica específica de

DIGNIDADE RE-VISTA | ISSN2525-698X| 2021 | V. VII | N. 12 | Educação Prática Libertadora - heranças dos 100 anos de Paulo Freire e Dom Paulo Arns. Pastoral Universitária Anchieta PUC-RIO. 
um poder que toma os indivíduos ao mesmo tempo como objetos e como instrumentos de seu exercício. Não é um poder triunfante que, a partir de seu próprio excesso, pode-se fiar em seu superpoderio; é um poder modesto, desconfiado, que funciona a modo de uma economia calculada, mas permanente. Humildes modalidades, procedimentos menores, se os compararmos aos rituais majestosos da soberania ou aos grandes aparelhos do Estado. E são eles justamente que vão pouco a pouco invadir essas formas maiores, modificar-lhes os mecanismos e impor-lhes seus processos. (Foucault, 1987, p.195)

O corpo faz parte da construção social do ser humano. E a partir dessa "pedagogia do medo" implementada sobre o corpo negro, que é uma forma de dominação e controle - baseada na punição e coerção -, a sociedade passa a repudiar esse corpo, e parte dela enxerga-o como inimigo. Com esse estereótipo formado, o corpo social tem total respaldo para qualquer tipo de discriminação a um jovem negro, principalmente se ele pertencer ao sistema carcerário. A filósofa e feminista negra Angela Davis ressalta a invisibilidade das questões que originam essa situação:

A prisão, dessa forma, funciona ideologicamente como um local abstrato no qual indesejáveis são depositados, livrando-nos da responsabilidade de pensar sobre as verdadeiras questões que afligem essas comunidades das quais os prisioneiros são oriundos em números tão desproporcionais. (2003, p.16-17)

Por sua vez, Maria Aparecida da Silva Bento parte da análise de Eugéne Enriquez (1997), traduzindo que as instituições são conservadoras e que buscam sempre reproduzir os mesmos indivíduos e comportamentos. Também afirma que "uma instituição tem como objetivo definir um modo de regulamentação, manter um estado, fazê-lo durar e assegurar a sua transmissão" (Bento, 2014, p.17). A Justiça Criminal influencia o processo de transformações políticosociais. A construção de um sistema legislativo, de códigos e regras, incluindo assim o Código Penal, complexo e de difícil entendimento, a falta de acesso a advogados e defensores de qualidade e com tempo para o atendimento, a morosidade, o tratamento desigual baseado no fenótipo são mecanismos utilizados como forma de garantir afastamento do processo de vítimas e réus. A resistência à transformação institucional explicita o esforço para manutenção de perspectivas hegemônicas e do controle pelos segmentos dominantes.

É preciso reconhecer que a condição racial daqueles que comandam o processo pode interferir na maneira como os programas são concebidos, como é feita a sua gestão no cotidiano de trabalho, como são definidas as 
prioridades, como/onde são alocados recursos, ou seja, nos processos de escolha de quais instituições serão parceiras e/ou de quais os profissionais vão operacionalizar esses programas. (Bento, 2014, p.22)

O aumento exponencial do índice de encarceramento, principalmente feminino, no Brasil, configura-se na construção de um sistema global que busca controlar corpos a fim de que se tornem úteis, também de forma lucrativa, para sustentar um sistema político baseado na acumulação de capital. Segundo os dados apresentados pelo Infopen Mulheres (2018), temos uma taxa de 40,6 mulheres presas no Brasil para cada grupo de 100 mil mulheres, tendo o país a quarta maior população feminina prisional do mundo. Em um período de 16 anos (2000 a 2016), a taxa de aprisionamento feminino aumentou em 525\% no Brasil. Pouco se conhece sobre o universo carcerário, sua complexidade e multidimensionalidade; isso gera uma visão superficial da realidade do sistema prisional, que alimenta de maneira errônea o senso comum. Compreendendo que decisões políticas são tomadas a favor de uma certa elite brasileira, sexista, classista e racista, desconsiderando assim as múltiplas vivências da população, atentar para processos políticos e políticas públicas que perpetuam um sistema de exclusão se faz necessário.

Ao analisarmos o sistema carcerário feminino, é indispensável que tratemos sobre perspectivas interseccionais, visto que nesse sistema reside um aspecto de sexismo e racismo institucionais. Ignorar a variável racial seria excluir a vivência e construção social da maioria das mulheres presas. Interseccionalidade (Crenshaw, 2002, p.177) é combinar dois ou mais eixos de subordinação, seja o patriarcalismo, desigualdades sociais, o racismo e outros sistemas discriminatórios, a fim de expor consequências estruturais dessa relação, que, como ações políticas, geram diversas formas de opressão partindo desses mecanismos.

As discriminações de raça e gênero produzem efeitos imbricados, ainda que diversos, promovendo experiências distintas na condição de classe e, no caso, na vivência da pobreza, a influenciar seus preditores e, consequentemente, suas estratégias de superação. Nesse sentido, são as mulheres negras que vivenciam estas duas experiências, aquelas sempre identificadas como ocupantes permanentes da base da hierarquia social. (Silva, 2013, p.109)

A contemporaneidade tem por lógica responsabilizar condutas individuais, não indo ao cerne da questão, não viabilizando políticas de ação coletiva para a construção de uma sociedade igualitária e justa, diminuindo assim a desigualdade de maneira eficiente. Condutas 
individuais são tratadas de maneira generalizada, a partir de conceitos, métodos, formulários, leis e manuais que enquadram indivíduos em um panorama geral.

Logo, o sistema criminal não é desprendido dos sistemas políticos e morais, são manifestações sociais atreladas ao campo jurídico e ao ordenamento social, que concretizam a estruturação hegemônica preterindo determinados grupos sociais face a outros. A diferença exorbitante das penas aplicadas por juízes sobre os indivíduos criminosos exemplifica a seletividade penal. A ocorrência de crimes cometidos por mulheres de diferentes classes comprova a capacidade de mulheres, mesmo com papéis sociais diferentes, de subverter uma ordem implícita no aparelho estatal que classifica o homem negro e pobre como criminoso. Ana Flauzina aponta que "não se pode interpretar o comportamento humano desvinculado das interações sociais que o atravessam" (2006, p.18). O cometimento de delitos são fatos sociais condicionados por fatores culturais e sociais, e não por características biológicas.

\section{Garantia dos direitos humanos para as jovens infratoras}

Ao pensar que o sistema carcerário foi criado a partir da lógica do patriarcado para corpos adultos e masculinos, excluindo totalmente as jovens, suas deficiências, orientação sexual, identidade de gênero, situação de gestação e maternidade, entre outros, surge-nos o questionamento sobre a eficiência desse sistema para este grupo, e se ele abrange todas as necessidades das adolescentes que ali vivem. Mesmo que as mulheres lutem por questões de igualdade de tratamento nas instituições, há certas questões que devem ser tratadas a partir do feminino. "As mulheres têm necessidades diferenciadas e este uso de respeito a um tratamento igual intensifica o contexto de violência que estas mulheres passam no contínuo desrespeito aos direitos humanos nas unidades prisionais" (Borges, 2018, p.95).

Como já citado, houve um aumento no encarceramento de adolescentes do sexo feminino, o que gerou a superlotação da única casa de medida socioeducativa feminina do Rio de Janeiro. O Mecanismo Estadual de Prevenção e Combate à Tortura do Rio de Janeiro (MEPCT/RJ) é um órgão vinculado à Assembleia do Estado do Rio de Janeiro e tem como objetivo realizar visitas periódicas em espaços de privação de liberdade para verificar as condições das penitenciárias, com meta de prevenir tratamentos cruéis às pessoas que estão em situação de privação de liberdade. O MEPCT/RJ (2016) apresentou um relatório temático sobre Mulheres, Meninas e Privação de Liberdade no Rio de Janeiro, levantando informações sobre a unidade do Departamento Geral de Ações Socioeducativas (Degase), localizada na Ilha do Governador, 
NEVES, Maria Carolina Cardim das. O hiperencarceramento brasileiro sob perspectiva de gênero e raças.

Dignidade Re-Vista, v.7, n.12, jul 2021.

DIGNIDADE

acusando-a de fugir das normas estabelecidas pelo Sinase e também pelas Regras de Bangkok (Conselho Nacional de Justiça, 2016). ${ }^{1}$

Por serem consideradas vulneráveis e incapazes, certas medidas de acolhimento deveriam ser tomadas para as jovens, de forma a levar em consideração as necessidades das adolescentes, como acesso à higiene pessoal, educação, alimentação, vestimenta, entre outros. Segundo o MEPCT/RJ (2016), o Estado só repassa à unidade a verba para o número ideal de infratoras, desconsiderando o número excedente de jovens. Desse modo, fica inviável garantir os direitos básicos dessas adolescentes, ferindo seus direitos humanos.

A superlotação por si só já se constitui em um tratamento cruel e desumano, acarretando uma oferta sobrecarregada de espaço e de serviço, comprometendo o atendimento técnico, além de todo maior quadro de tensão que se gesta neste quadro. (MEPCT/RJ, 2016, p.61)

Outro fato apontado foi a localização da casa de detenção. De acordo com a Regra de Bangkok número 4 (Conselho Nacional de Justiça, 2016, p.22), a casa de detenção deveria ficar próxima ao meio familiar e social que a adolescente pertencesse, de forma que isso ajudasse no processo de ressocialização, além de garantir o acompanhamento e a interação de seus familiares. Com a única unidade localizada na Ilha do Governador, alguns familiares se deslocam de longe para visitar as detentas - e o que acontece, por conta da falta de dinheiro ou auxílio, é que muitos familiares deixam de visitá-las. Assim, também a distância entre a moradia e a unidade socioeducativa acaba impossibilitando a criação e desenvolvimento de projetos com os familiares, que são deveres do Degase justamente por conta dessa distância.

\section{Metodologia educativa e sua implementação}

As casas de medidas socioeducativas são espaços que se caracterizam como lugares de correção, instituídos para disciplinar jovens através de um processo educativo. No Rio de Janeiro, elas se encontram sob tutela da Secretaria de Educação do Estado. Contudo o índice de reincidência desses jovens para o crime é grande, enquanto a eficiência no processo de educação escolar se encontra em mau funcionamento.

\footnotetext{
${ }^{1}$ As Regras de Bangkok são normas internacionais que objetivam zelar pelas mulheres em situação de encarceramento, atentando para o tratamento das instituições para com as infratoras.
}

DIGNIDADE RE-VISTA | ISSN2525-698X| 2021 | V. VII | N. 12 | Educação Prática Libertadora - heranças dos 100 anos de Paulo Freire e Dom Paulo Arns. Pastoral Universitária Anchieta PUC-RIO. 
Lembramos que falamos de um sistema institucional que, para funcionar, aglutina e marca determinados grupos-sujeitos, como por exemplo, os agentes penitenciários e socioeducativos, as mulheres e as adolescentes, e a equipe técnica (Profissionais de diversas áreas de saber como: Psicologia, Serviço Social, Pedagogia, entre outros); estes grupos são separados por diferentes sistemas de poder que se relacionam, compõem a instituição de privação de liberdade. (MEPCT/RJ, 2016, p.13)

“Ao pensar na obsolescência do sistema prisional, devemos nos perguntar como tantas pessoas foram parar na prisão sem que houvesse maiores debates sobre a eficácia do encarceramento" (Davis, 2003, p.12.). O jovem periférico está inserido em um meio excludente da sociedade marcado pela vulnerabilidade social, onde vive constantemente em situações de violência, seja por parte do Estado, seja por grupos paramilitares ou traficantes, com a falta de saúde básica, educação, moradia digna, direitos básicos que deveriam ser garantidos pelo Estado, conforme o Estatuto da Criança e do Adolescente (ECA) (2017, p.20.) ${ }^{2}$. A coletividade ainda o coloca em um sistema de reclusão que gera grande instabilidade mental e emocional.

Sabendo que são recorrentes os conflitos entre os menores e os agentes socioeducativos e servidores da instituição, e que estes detêm certa autonomia para aplicar sanções aos adolescentes, questionar a aplicação do projeto de Lei $\mathrm{n}^{\circ} 1.825 / 16$, que permite o porte de armas para agentes de segurança socioeducativos (Rio de Janeiro, 2016), é fundamental. O relatório Mulheres, Meninas e Privação de Liberdade no Rio de Janeiro apresenta a situação de humilhação que as jovens infratoras passam no relacionamento com os servidores:

\begin{abstract}
Além dos agentes da unidade, as adolescentes relataram que é comum a intervenção de agentes pertencentes à Coordenação de Segurança e Inteligência (CESINT). Essa coordenação chefiada pelo agente penitenciário Sr. Leonam Leão funciona como uma espécie de "serviços especiais" que atuam em situações de distúrbios nas unidades socioeducativas. Foram relatados inúmeros episódios envolvendo a intervenção do CESINT, tais como uso excessivo da força, xingamentos e tortura. Segundo informação, este grupo se encontra na unidade de forma rotineira e muito de seus componentes costumam almoçar no refeitório do PACGC, apresentam o uniforme preto contendo uma série de artefatos de contenção, e são conhecidos por extrema truculência em suas ações. (MEPCT/RJ, 2016, p.65.)
\end{abstract}

Estatuto da Criança e do Adolescente, 2017, p.20.

Art. 4 É dever da família, da comunidade, da sociedade em geral e do poder público assegurar, com absoluta prioridade, a efetivação dos direitos referentes à vida, à saúde, à alimentação, à educação, ao esporte, ao lazer, à profissionalização, à cultura, à dignidade, ao respeito, à liberdade e à convivência familiar e comunitária.

DIGNIDADE RE-VISTA | ISSN2525-698X| 2021 | V. VII | N. 12 | Educação Prática Libertadora - heranças dos 100 anos de Paulo Freire e Dom Paulo Arns. Pastoral Universitária Anchieta PUC-RIO. 
NEVES, Maria Carolina Cardim das. O hiperencarceramento brasileiro sob perspectiva de gênero e raças. Dignidade Re-Vista, v.7, n.12, jul 2021.

\section{DIGNIDADE

O exagero no tratamento dos funcionários mediante agressões físicas recorrentes, os xingamentos relacionados ao gênero feminino, hipersexualizando seus corpos, a utilização desnecessária do spray de pimenta e algemas demonstram um cenário de profundo desrespeito aos direitos humanos das adolescentes privadas de liberdade. O Estatuto da Criança e do Adolescente salienta:

Art. 18-A. A criança e o adolescente têm o direito de ser educados e cuidados sem o uso de castigo físico ou de tratamento cruel ou degradante, como formas de correção, disciplina, educação ou qualquer outro pretexto, pelos pais, pelos integrantes da família ampliada, pelos responsáveis, pelos agentes públicos executores de medidas socioeducativas ou por qualquer pessoa encarregada de cuidar deles, tratá-los, educá-los ou protegê-los (Incluído pela Lei $n^{\circ}$ 13.010, de 2014). (2019, p.22)

Segundo a cientista política Marta Arretche (2002, p.9), a eficácia da implementação de uma política pública se estabelece realmente por meio dos implementadores de fato e não por meio dos que a formularam, pois aqueles têm um maior contato com o objeto e as situações que o circundam. E esses implementadores baseiam-se em suas próprias referências e visão de mundo para a tomada de decisão ao desempenhar suas funções.

\section{Mulheres negras: pobreza e desigualdade de renda}

A grande desigualdade entre os grupos sociais (mulheres negras, mulheres brancas, homens negros e homens brancos) está relacionada ao pertencimento racial, levando em consideração apenas as variáveis de gênero e raça. Em 2009, a extrema pobreza era vivenciada por $48 \%$ dos homens, $52 \%$ das mulheres, e, aproximadamente, $74 \%$ desse contingente era constituído por pretos, pardos e indígenas, sendo que a pobreza era experimentada por $21 \%$ das mulheres negras. Após dez anos, não houve uma melhora significativa na vida da mulher negra no Brasil. Conforme a Pesquisa Nacional por Amostra de Domicílios (PNAD) (2019), no $1^{\circ}$ trimestre de 2019, 63,9\% dos desocupados no Brasil eram pretos ou pardos, e a taxa de desocupação das mulheres foi 36,7\% maior que a dos homens. A presença negra nos estratos inferiores da distribuição de renda (pobres e extremamente pobres) é sempre maior que o dobro da participação da população branca. Referente às pessoas abaixo da linha de pobreza em 2018, a população branca representava $15,4 \%$, e pretos ou pardos correspondiam a 32,9\%. E enquanto $34,6 \%$ das pessoas de cor ou raça branca estavam em ocupações informais, entre as de cor ou 
NEVES, Maria Carolina Cardim das. O hiperencarceramento brasileiro sob perspectiva de gênero e raças.

Dignidade Re-Vista, v.7, n.12, jul 2021.

raça preta ou parda esse percentual atingiu 47,3\%. Em relação à renda, a mulher negra ganhava $44,4 \%$ menos do que o homem branco.

Segundo Davis (2003), o envolvimento corporativo no sistema prisional não é o único a sofrer com a economia capitalista. Políticas relacionadas ao bem-estar social foram sendo desarranjadas, absorvidas por corporações, ocorrendo a privatização de serviços anteriormente geridos pelo governo. A autora ainda destaca que a lógica capitalista gere o sistema punitivo, a construção de penitenciárias orientada por padrões de privatização, que também recaem na educação, saúde e outras áreas das vidas humanas. No contexto brasileiro, a contenção de recursos públicos voltados para população, como o Sistema Único de Saúde, Farmácia Popular, e o congelamento do orçamento do sistema educacional público financiam a privatização de serviços que antes eram geridos pelo Estado e mais facilmente acessados pela população das camadas de base.

A configuração econômica capitalista e a expansão do sistema prisional influenciam diretamente a vida de mulheres negras. Segundo o Infopen Mulheres (2018), em junho de 2016, a população prisional feminina atingiu a marca de 42 mil mulheres privadas de liberdade, o que representou um aumento de $656 \%$ em relação ao total registrado no início dos anos 2000 . O levantamento ainda sinaliza que $62 \%$ da população prisional feminina era composta por mulheres negras e que 3 em cada 5 mulheres que se encontravam no sistema prisional respondiam por crimes ligados ao tráfico. Contudo, $45 \%$ das mulheres presas no Brasil não haviam sido julgadas ainda. Apenas $15 \%$ da população prisional feminina concluiu o ensino médio e podemos afirmar que $50 \%$ da população prisional feminina é formada por jovens.

O site Mulheres em Prisão alerta sobre a falta de conhecimento e de preparo do Poder Judiciário para lidar com as mulheres que participam do mercado ilegal de drogas:

Mas muitas vezes a criminalização das atividades desempenhadas pelas mulheres não leva em conta que elas têm a pior remuneração dentro do comércio de drogas e parece ignorar que existe uma incontestável assimetria de gêneros. As desigualdades entre homens e mulheres observadas no mercado de trabalho são ainda mais acentuadas no mercado ilegal.

Ao serem julgadas pelo envolvimento com o tráfico, elas são duramente penalizadas por pequenas atividades, como transporte de drogas. E não raramente apresentam discursos parecidos quando indagadas sobre o porquê de terem enveredado por tal caminho. Seus relatos mostram que o objetivo era obter remuneração para cuidar do lar e arcar com compromissos relacionados à família, principalmente aos filhos, quando não viam expectativas na economia formal. Algumas afirmam, inclusive, que desenvolviam outras atividades remuneradas, muitas vezes informais, mas sem qualquer relação

DIGNIDADE RE-VISTA | ISSN2525-698X| 2021 | V. VII | N. 12 | Educação Prática Libertadora - heranças dos 100 anos de Paulo Freire e Dom Paulo Arns. Pastoral Universitária Anchieta PUC-RIO. 
com o crime - em paralelo ao envolvimento no comércio ilegal, mas que não alcançavam o necessário para suprir as demandas da casa e dos seus dependentes. (Mulheres em Prisão)

As cadeias do Brasil estão longe de serem consideradas as melhores dentro dos padrões mundiais. A superlotação, a falta de estrutura, o sistema precário de saúde e higiene, entre outros, são exemplos de que os presidiários estão carentes dos direitos humanos. Esse conjunto de precariedades reflete o cárcere feminino: ausência de políticas públicas em gênero e raça voltadas às encarceradas. Pouco é falado e estudado sobre o encarceramento de mulheres, principalmente pelo fato de ser um número menor, pela questão do gênero e pela grande maioria pertencer a uma classe excluída da sociedade. Porém, o número de mulheres em medida de privação de liberdade vem crescendo nos últimos anos, de maneira superior ao encarceramento de homens. Com isso, faz-se necessário, mais do que nunca, tirar esse assunto da invisibilidade, trazendo o debate para o centro das discussões.

Sabemos que a pena privativa de liberdade tem impacto especialmente na família da pessoa encarcerada. Quando tratamos do encarceramento feminino, a questão é mais complexa, dado que as mulheres negras são as principais responsáveis pelas tarefas ligadas à esfera financeira e aos afazeres domésticos ou ao cuidado de crianças, idosos e pessoas doentes em geral, mesmo que também exerçam trabalho remunerado.

Segundo o InfoPen Mulheres (2018, p.22), apenas 7\% dos presídios são destinados ao público feminino e outros $16 \%$ são caracterizados como mistos, gerando visitas muito custosas e desgastantes. As famílias que são especialmente afetadas pelo encarceramento de mulheres possuem um padrão quanto à raça, gênero e localização geográfica. Em 2010, de acordo com o Instituto Brasileiro de Geografia e Estatística (IBGE), nos dois maiores municípios brasileiros, São Paulo e Rio de Janeiro, a chance de uma pessoa preta ou parda residir em um aglomerado subnormal era mais do que o dobro da verificada entre as pessoas brancas. Assim, as consequências do encarceramento feminino não atingem de forma homogênea a sociedade, pelo contrário, impactam diretamente as mulheres negras moradoras de periferias, intensificando sua situação de vulnerabilidade social.

Como já exposto, a mulher negra é a que menos ocupa trabalhos formais, e cabe a ela encontrar caminhos para sua sobrevivência. A maioria encontra-se em trabalhos de baixa remuneração, informais e de extrema vulnerabilidade. Acrescentando-se a isso o estigma estereotipado de uma ex-presidiária, a falta de credibilidade no seu lado profissional, a suposta 
periculosidade, que é reforçada por uma mídia sensacionalista, dificulta-se ainda mais sua inserção no mercado de trabalho. A falta do acolhimento social e do preparo estrutural para receber essa pessoa de volta em ambientes não só profissionais, mas também acadêmicos, afetivos, lugares de prestígio no geral, incentivam a reincidência ao crime. $\mathrm{O}$ coletivo de mulheres egressas do sistema carcerário "Eu sou eu" aponta:

Nós, assim como os adolescentes, também saímos da prisão. Estamos envoltos em trabalhos, estudos, cuidados familiares, viagens para fins de palestras, ativismo no campo das políticas criminais e seguindo por aí, vinculados aos nossos familiares, com laços afetivos, sociais e fraternos bem atados. Nossa missão, logo que o portão da cadeia foi aberto, é de seguir adiante reconstruindo e ressignificando as dores que sofremos e os estigmas que nos são impostos. (Eu sou Eu, 2019)

O governo brasileiro não garante políticas emancipatórias para que a população alcance a equidade social e isso acaba por recair sobre parcela dos cidadãos. É nesse sistema reorganizado que o racismo continua se perpetuando em um novo padrão mais violento e que não quer apenas o controle do corpo negro, mas também seu extermínio simbólico e físico. A violência, as desigualdades e a discriminação são naturalizadas na percepção de uma sociedade que tem o Estado como provedor da segurança, do domínio e detentor poder. O Estado naturaliza o extermínio do indesejável por meio da implantação de uma cultura que preza o domínio e o controle do outro, a fim de garantir o bem-estar de um grupo considerado legítimo.

A incongruência entre os objetivos da instituição e o modo de agir dos servidores, a precária estrutura do local, a falta do relacionamento familiar e comunitário acarretam a ineficácia da ressocialização das pessoas em privação de liberdade e acabam por legitimar a violência institucional e de gênero contra a mulher, ferindo seus direitos e prejudicando, assim, o desenvolvimento individual e como cidadãs dessas mulheres. A principal função da instituição, que é de evitar a repetição do delito, acaba por se tornar falha diante das circunstâncias apresentadas. Falta a apresentação de uma nova perspectiva de vida, com seus direitos e deveres assegurados. Os agentes do Governo, que deveriam ser exemplos de respeito e dignidade, não passam confiança para essas mulheres, mas criam a imagem de um governo autoritário e perverso. A negação de seus direitos sociais, religiosos, políticos e dos seus saberes demonstram um afastamento do Estado com a população que mais carece dele. 


\section{Referências bibliográficas}

BENTO, M. A. S. Notas sobre a expressão da Branquitude nas Instituições. In: BENTO, M. A. S.; SILVEIRA, M. J.; NOGUEIRA, S. G. (orgs.). Identidade, branquitude e negritude: contribuições para a psicologia social no Brasil: novos ensaios, relatos de experiência e de pesquisa. São Paulo: Casa do Psicólogo, 2014.

ALMEIDA, S. Capitalismo, raça e racismo estrutural no Brasil. In: ALMEIDA, S.; PIRES, T.; PINTO, A.; SOUZA, R.; PACHECO, R. (orgs.). Diálogos sobre gênero, raça e classe no Brasil. Rio de Janeiro: Selo Luísa Mahin, 2019. p.16-22.

ARRETCHE, M. Uma contribuição para fazermos avaliações menos ingênuas. BARREIRA, M. C. R. N.; CARVALHO, M. C. B. (orgs.) São Paulo: IEE/PUC, 2002. Disponível em: $<$ https://marialuizalevi.files.wordpress.com/2015/05/arretche_2002-menos-ingenuidade.pdf>. Acesso em: 4 abr 2021.

BORGES, J. O que é encarceramento em massa? São Paulo: Letramento, 2018.

BRASIL. Projeto de lei anticrime: anteprojeto de lei no , de 2019. Brasília, 2019. Disponível em: < https://www.justica.gov.br/news/collective-nitf-content-1549284631.06/projeto-de-leianticrime.pdf $>$. Acesso em: 19 abe 2021.

BRASIL. Lei n$^{\circ} 11.343$, de 23 de agosto de 2006. Institui o Sistema Nacional de Políticas Públicas sobre Drogas. Brasília, 2006. Dispoível em: http://www.planalto.gov.br/ccivil_03/_ato2004-2006/2006/lei/111343.htm Acesso em: 4 abr 2021.

CONSELHO NACIONAL DE JUSTIÇA. Regras de Bangkok: regras das Nações Unidas para o tratamento de mulheres presas e medidas não privativas de liberdade para mulheres infratoras. Coordenação: Luís Geraldo Sant’Ana Lanfredi. Brasília: CNJ, 2016. Disponível em: <https://www.cnj.jus.br/wpcontent/uploads/2019/09/cd8bc11ffdcbc397c32eecdc40afbb74.pdf>. Acesso em: 8 mar 2021.

CRENSHAW, K. Documento para o encontro de especialistas em aspectos da discriminação racial relativos ao gênero. Estudos feministas, ano 10, p.171-188, 2002. Disponível em: <https://www.scielo.br/j/ref/a/mbTpP4SFXPnJZ397j8fSBQQ/?format=pdf\&lang=pt>. Acesso em: 4 fev 2021.

DAVIS, A. Estarão as prisões obsoletas? Rio de Janeiro: Bertrand Brasil, 2018.

ECA. Estatuto da criança e do adolescente. Brasília: Conanda, 2019. Disponível em: <https://www.mdh.gov.br/todas-as-noticias/2019/maio/governo-federal-lanca-nova-edicaodo-estatuto-da-crianca-e-do-adolescente-eca/ECA2019digital.pdf > . Acesso em: 15 mar 2021.

EU SOU EU. Nós, assim como eles, também saímos da prisão. 2019. Disponível em: $<$ https://ongeusoueu.wixsite.com/website/inicio/n\%C3\%B3s-assim-como-elestamb\%C3\%A9m-sa\%C3\%ADmos-da-pris\%C3\%A3o>. Acesso em: 4 abr 2021. 
NEVES, Maria Carolina Cardim das. O hiperencarceramento brasileiro sob perspectiva de gênero e raças.

Dignidade Re-Vista, v.7, n.12, jul 2021.

DIGNIDADE

FLAUZINA, A. Corpo negro caído no chão: o Sistema Penal e o projeto genocida do Estado Brasileiro. Brasília: Brado, 2019.

FOUCAULT, Michel. Vigiar e Punir: nascimento da prisão. Trad. R. Ramalhete. Petrópolis: Vozes, 1987. Disponível em: < https://www.ufsj.edu.br/portal2repositorio/File/centrocultural/foucault_vigiar_punir.pdf>. Acesso em:21 fev 2021.

IBGE. Pesquisa Nacional por Amostra de Domicílios Contínua. Mercado de Trabalho Brasileiro. $1^{\text {o }}$ trimestre de 2019. 16 de maio de 2019. IBGE. Disponível em: $<$ https://agenciadenoticias.ibge.gov.br/media/com_mediaibge/arquivos/8ff41004968ad363064 30c82eece3173.pdf>. Acesso em: 12 abr 2021.

INFOPEN MULHERES. Levantamento nacional de informações penitenciárias. 2.ed. SANTOS, T. (org.). ROSA, M. I. et. al. (colab.). Brasília: Ministério da Justiça e da Segurança Pública. Departamento Penitenciário Nacional, 2018.

MEPCET/RJ. Relatório temático: mulheres, meninas e privação de liberdade. Rio de Janeiro: ALERJ, 2016. Disponível em: <https://www.cressrj.org.br/wpcontent/uploads/2016/03/Mulheres.pdf>. Acesso em:4 fev 2021.

MULHERES EM PRISÃO. Quem são essas mulheres? Disponível em: $<$ http://mulheresemprisao.org.br/quem/>. Acesso em: 22 mai 2021.

RIO DE JANEIRO. Projeto de Lei $n^{\circ}$ 1.825/2016: dispõe sobre o porte de arma de fogo para agentes de segurança socioeducativos do Departamento Geral de Ações Socioeducativas do Estado do Rio de Janeiro. Rio de Janeiro: Alerj, 2016. Disponível em:

<http://alerjln1.alerj.rj.gov.br/scpro1519.nsf/e00a7c3c8652b69a83256cca00646ee5/43f20f0a6 7cfc25683257fc4004b4c2d?OpenDocument>. Acesso em: 2 mai 2021.

SILVA, T. D. Mulheres negras, pobreza e desigualdade de renda. In: MARCONDES, M. M. et al. Dossiê mulheres negras: retrato das condições de vida das mulheres negras no Brasil. Brasília: Ipea, 2013.

SINASE. Levantamento anual 2016. Brasília: Ministério dos Direitos Humanos, 2018.

Disponível em: <https://www.mdh.gov.br/todas-asnoticias/2018/marco/Levantamento_2016Final.pdf>. Acesso em: 10 jan 2021.

WAISELFISZ, J.J. Mapa da violência 2016: homicídios por armas de fogo no Brasil. [S. l.]: Flacso Brasil, 2016. Disponível em:

<https://flacso.org.br/files/2016/08/Mapa2016_armas_web-1.pdf >. Acesso em: 3 jan 2021.

DIGNIDADE RE-VISTA | ISSN2525-698X| 2021 | V. VII | N. 12 | Educação Prática Libertadora - heranças dos 100 anos de Paulo Freire e Dom Paulo Arns. Pastoral Universitária Anchieta PUC-RIO. 